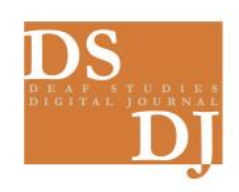

\title{
The Transformative Impact of Deaf Studies on Law and Policy
}

\author{
Deaf Studies Conference Transformations Proceedings
}

\section{Tawny Holmes Hlibok}

Gallaudet University, www.gallaudet.edu

Tawny.holmes@gallaudet.edu

\begin{abstract}
A panel featuring Deaf lawyers from various fields (health, telecommunications, civil rights, education) to discuss the impact of Deaf Studies' findings on their day to day work on effectuating policy changes in both the private sector and government-level work.

Moderated by Tawny Holmes Hlibok, Esq., Education Policy Counsel, NAD and Assistant Professor, Department of ASL and Deaf Studies

Zainab Alkebsi, Esq., Federal Policy Counsel, NAD

Dr. Opeoluwa Sotonwa, LL.M., LP. D, Executive Director, Missouri Commission for the Deaf and Hard of Hearing

Howard A. Rosenblum, Esq., CEO, NAD

Dr. Joseph Murray, Vice-President, WFD and Associate Professor, Department of ASL and Deaf Studies
\end{abstract}

\section{Keywords}

Deaf Studies, Deaf lawyers, policy changes, health, telecommunications, civil rights, education

\section{Presentation Transcript}

Tawny Holmes Hlibok: On our panel are Deaf attorneys who are involved with advocacy and activism in different fields like communication, international work, health, civil rights, education, and more. Each panelist will discuss what they've seen that impacts Deaf Studies from their daily work working with clients, the court system, and the government. All of our panelists have a common goal of positive policy change for Deaf signers. All right. We'll go ahead and introduce our panelists. I am Tawny Holmes Hlibok. The role I have here at Gallaudet is teaching in the ASL and Deaf Studies Department. I also wear another hat, working with the National Association of the Deaf as their education policy attorney. I will be your moderator today. This is Zainab Alkebsi, who works at the National Association of the Deaf (NAD) as a policy attorney. My focus is on education, and her focus is on everything else. Next is Opeoluwa Sotonwa, who works at the Missouri Commission for the Deaf, located in the central section of the United States. 
He is the executive director and an attorney, and holds a Ph.D. as well. Next is Howard Rosenblum, also an attorney himself and the CEO of the NAD here in the United States. Finally, we have Joseph Murray, whose name sign is [demonstrates name sign for each of the panelists] ... Joseph works for the World Federation of the Deaf as the vice president on a voluntary basis. His "real" job is teaching in the ASL and Deaf Studies Department. Did any of you want to add anything, or are we all set?

Panelists: All good.

THH: All right. We will have a total of six questions for the panel. The first question is for all of the panelists to answer. After that, I will allow whoever wants to answer all subsequent questions. After that, I will allow the audience to ask them questions. All right? Okay. Our first question is: from what you've seen so far in society and deaf people's lives, what kind of changes have you seen in your work?

Zainab Alkebsi: Are we starting with me or Joseph? Joseph, you can go ahead if you want.

Joseph Murray: Sure, if you want. Do you want me to stand or sit?

THH: It seems they prefer you stand.

JM: Everyone can see me? I have to stand up? I thought I was tall enough? Is this better? Should I stand on the chair? No! So, from a world view, one thing impacts me deeply everywhere I go around the world, which is that sign language used to be shameful. People would sign out of sight and secretly. But now there's pride. Real pride, and it's also a tool for equality. Back then, we signed in secret, wouldn't admit to using sign language, and were ambiguous about using it. Today, people around the world are fighting to get legal recognition of sign language. Today there are 45 countries that have legally recognized sign language. 45 ! 45. [applause] Where do you think the first country in the world to get legal recognition was? Which continent do you think it was? Europe? North America? How many of you think it was Europe? Raise your hands. Most of you. How many think it was Asia? Just a few. South America? Some. Africa? You're right! It was Africa - specifically, Uganda. Uganda was the first country that gained recognition of sign language. And then that started - that was back in 1995, and after that, there were more and more countries that recognized sign language. We have 45 countries now, but in the world, there are 193 countries. I'm sorry, officially, 192 countries. 192 countries. So we have 45. Which continent do you think has the most countries recognizing sign language? North America? North America? All three countries? No. Europe. Yes, it's Europe. They've fought really hard, but there are also other locations. This morning, keynote speaker Maartje DeMeulder, who's sitting back there - and I worked with Rachel McKee to collect case studies on sign language laws passed around the world. We noticed a variety in the laws. Some are constitutional recognition, while others are state-level, like here in the United States. Yet others are local recognition; there are many of those. But the point is this is all about pride, the pride of having language and knowing that language can be a tool for equality. That is powerful. That's the biggest change I've seen so far. 
THH: Who would like to go next?

Howard Rosenblum: Ope? Okay. Hello. I'm Howard. That's a tough act to follow! He responded through a global perspective. My response will focus on the United States of America. I've been an attorney for 26 years. I love to sue hearing people.

ZA: Yes, that's true.

HR: Joseph referred to policies and recognition. Here in America, there is no recognition of ASL as a language. The perspective is different here, but many laws have been established requiring the provision of signed communication, instruction, interpreting, health care, and more, which has opened more doors. One good example I can share is from when I was a little boy. I met the only deaf lawyer in America. He was the only one, and he was in Chicago, my hometown. I looked up to him, and he inspired me to become an attorney as well. I wanted to be just like him and sue people. I became a lawyer before the Americans with Disabilities Act (ADA) was established in 1990. Really, it became active in 1992 and onwards. I became a lawyer in 1992, before ADA. However, prior to that, there was another law enacted in 1973, which opened some doors. Keep in mind that in America, we have Gallaudet, NTID and CSUN, which was great, but none offered a law school nor a medical school. That meant if a Deaf person wanted to become either an attorney or a doctor, they had to attend a public school with interpreters. Before the ADA, if a Deaf person wanted to attend a hearing university, they would not be given any form of communication access, nor did any of them have to accept Deaf students. After the 1973 law, and later on after the ADA law was passed, that opened many more doors for Deaf people who now had rights and communication access. Do you know how many Deaf lawyers there are in America now? [Someone in the audience immediately said 400.] You are correct. There are over 400 attorneys. Imagine that. In the 1960s there was only one, and today we have 400. That means the same can be true for all over the world. The most vital thing is having access. Deaf people always can do things, but the only issue is having access. That's it. If we have access, then we can.

THH: Thank you.

Opeoluwa Sotonwa: I'm going to start with Deaf President Now (DPN). How many of you know about DPN? That took place here at Gallaudet 30 years ago. That, to me, really started as an issue and led to a protest because Deaf can. That message was sent to people all over the United States and the world, too. Now we have different state commissions for Deaf and hard of hearing people. Most of them are led by Deaf and hard of hearing people themselves. There are also Deaf businesses and leaders all over the country. That really shows how Deaf people can do things. That started from Deaf studies and Deaf pedagogy. That helped us identify issues and learn from them. Also, from a policy practice and perspective, we may know what we need, what we know, and what we want when we pass laws, but how do we discuss our needs?

HR: Right. 
OS: That is the key. We need to find information from experts, researchers, and Deaf scholars to really help us. Also, attorneys who plan to file cases often aren't familiar with some things, so we call experts and witnesses to show why we need something. We often read articles that really help and influence us in making sure we take proper action. That has made us who we are today. Really, the transformation has been quite notable and huge. I think the future is bright for us.

THH: Thank you. Zainab?

ZA: Can you see me? Great. Howard has already explained the laws we have here in the United States that have been opening doors. For example, I became a lawyer because of those laws opening for me. I want to take a moment and explain how those laws helped change the face of the deaf community here in the United States and threw the door wide open to access. One of the vial points is technology. For example, we began requiring that people use the phone, or TTY, where we could type on the phone, and spanning all the way up to today, where we have video relay services (VRS) where we can sign. We have the right to access the phone. Now we have television, which we access via captions. Laws helped make this a requirement. We started with having decoders on top of TVs, and today we have captioning online. That's another example of how laws have helped us, through technology innovations. But is that enough? No. We still need more innovative technology. We need to continue to open even more doors and ensure more access. And we have transportation. For example, transportation has a few requirements for accessibility, which are hardly adequate. We keep on advocating for greater requirements, but we keep on pushing barriers. Now, I think it was two years ago, we pushed airline companies because we wanted captions on the plane. Because the law just says it's enough for stewardesses to explain instructions to passengers and nothing more. Televisions on the back of seats on planes have no captions. There are a lot of gaps. There is no system in place to inform deaf people when to board. As I said, gaps. That's not acceptable, and we've told them that they're not doing enough. We conferred with airlines and they agreed to make captions available for the seat televisions, but we're still pushing for visual announcements - we're still fighting for that. Knowing when we're to board, airport accessibility systems, and so on. That is an example of how law, advocacy, and technology come together in terms of our work. So the world Opeoluwa is right, the future is bright, but we still have a long way to go. We have to keep going, and we can't give up. We can't say, "But we have laws and we have technology." No. We must keep pushing barriers and fighting for that. Thank you.

THH: Thank you. Some of you mentioned the importance of research. Now, I'm curious. Do you see research being used for positive policy and law changes, or do law and policy changes influence research? Which holds more weight? The many presenters, researchers, and authors here might want to know how you see their work impacting you. I'm curious about that.

ZA: I'll go ahead and answer first. Okay, so in my role as a policy attorney at NAD, I'm responsible for working with federal agencies. There are many federal agencies here in the United States. One focuses on communication like phones and television, another focuses on transportation, and another focuses on ADA and the law like he mentioned, justice, and so on. My role is that I must interact with them and explain what language they need to include, and what is missing, and support that language or not. How do I do that? 
I have meetings and I file comments. What helps me with that is data. It's not enough for me to just say, "I need this and that." We have to show them actual data, so they can review it. That helps us make our case, and they will then be more willing to write in the language what we need. So data really helps my policy work and interaction with them. Not only with those agencies, but also with private companies. I can show them data and explain why they need to include this information in their business. So it really does play a crucial role.

THH: That's interesting. So that means data and research are used to support your work and validate your arguments why laws need to change?

ZA: Yes. We always need more data. Sometimes when I write something or have meetings, I see that I need more data to show. Really, the more data and research we have, the more it will influence our work. Yes.

THH: Do you have any thoughts to add?

JM: Yes. It's interesting. They chose their jobs, I chose my job, and I think many of you chose your jobs because you want to change the world, right? We don't want things to always be the same; we want to change the world. Right? Right. We want to change the world. During my younger days when I was figuring out what to do with my future, I thought I wanted to work in politics. I could change the world through politics. So with that decision, I got a position with Senator Ted Kennedy as part of his education staff, since he was on the Committee for Education. I worked in the Senate for nine months. I wanted to change the world. They would make laws, and I worked under a lot of people. I saw that before they wrote their laws, they would look at the newest academic research and ideas, revise their language, and then create laws. So my job at the Senate was a sausage maker. I'd collect information and then they'd create the end product. I realized that if I wanted to change the world, I should look to academics and create ideas to pass on to people who create laws that are passed, which then influences change. So my answer to this question is, yes, you Deaf Studies scholars and academics, your ideas are given to people at WFD, NAD, and so on. The information we receive helps us in our work. WFD has what is called expert working groups - we sign it this way. There are different specialties such as education, human rights, and technology. Some of you in this room are experts. In fact, Tawny is one of them -

THH: Yes.

JM: - for education. Yesterday at Ben's presentation about WFD's work, he showed a list of policies. Who wrote those policies? WFD expert working groups and different academics who were brought in to work with the experts. That helped WFD tremendously. I went to the UN and when they asked me why sign language was necessary, I could explain to them about language acquisition and language deprivation, and I know my facts are right. They know WFD is telling the truth because of our academic research. That kind of collaboration is a must. Your work, when it is published might seem insignificant, but it is power. Publishing is spreading your ideas, and giving it to us. Publishing is power, I'm telling you. 


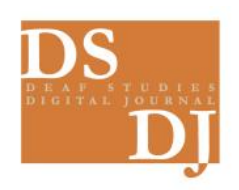

THH: Wow. I'm sure that applies to every country's agency. That concept is true for all over the world. Yes. Opeoluwa?

OS: Often I notice, from policy itself... the issue I see sometimes is not how you write about research, not how we come up with policy because research depends on theories and more educational things. People write to develop awareness. But in the policy world, how you frame it makes a difference. Does it match other people's needs? Could people who are not Deaf buy into our ideas? Often in Missouri, we've had some representation. In the four years at my job, we passed 28 laws. My office worked on that, but really, if you look at the bills themselves, very few - maybe six or seven - are labeled as "Deaf" bills. We had to frame them as Missouri agendas, even though technically they supported the Deaf agenda. I had to try and work hard to promote Deaf people's interests, but I realize that the research we have now is more focused on how to promote existing Deaf interests, such as empowerment, advocating for Deaf rights, yes. But how policy is made and how it works is that we should involve other people as well. So we have to sell it to get their buy-in for other people. We have to design it and frame it in another way. I think that's missing in Deaf Studies. Maybe it is time for us to really consider how we can do research in a way that other people, academics, policy groups, and think tanks can focus on and buy into our interests, too. Secondly, I also have noticed emerging issues all over the community in the United States itself. We haven't had the right foundation or resources to support our knowledge. For example, issues like immigration - does our group of people write about or study how immigration impacts Deaf people? And make recommendations? Secondly, soon - I predict within the next 25 years - we might have many replacements for interpreters, such as robots or AI, artificial intelligence. That's coming soon. Now who are people making policies for? Themselves. What I call hereditary hegemony — what does that mean? The power of policymakers who make decisions in a system designed by hearing people. And who invests in that? Often, companies. We, the Deaf community, lack awareness about that. When that expands, that's when we'll start complaining. My recommendation today is to try and make an effort right now to start thinking about AI and how it will impact the future of Deaf people's communication access. There's potential for more research on that. Thirdly, another issue I have recognized in my line of study on Deaf lives and Deaf experiences during police interrogations is that I've found a lot of research in that system, but we need to bring up that information as policies to the Department of Justice and similar entities. That's what I want more of, yes. Just throwing that in.

THH: Interesting. I want to respond to that. Opeoluwa brought up an interesting point about the impact of AI and how that area needs more research. With that research, we will know about both pros and cons and both perspectives. That's something we can consider. Sometimes companies will proceed with certain things, but how does the Deaf community feel? What about our experiences, positive or negative? We need to document that so that we can advocate to perhaps effect changes based on our preferences, from our actual experiences. That's what I visualize. Howard, did you want to add something? 
HR: Yes. A few examples. Zainab mentioned technology and policy and how your research helps us. I want to share an example. There are many Deaf people in prison here in America. Many prisons refuse to provide interpreters or videophones. That means Deaf prisoners are living in isolation and have no communication. I've visited some prisoners myself. I visited a Deaf man in prison - at the time I was living in Chicago, Illinois. When I visited, there were no other Deaf prisoners in that area so that man was alone. Interpreters weren't allowed. He was sentenced to life for murder. Regardless of the crime, communication access still is a must. So when I visited, I noticed they wouldn't let him communicate because he was handcuffed in the front. That wasn't deaf-friendly. They had to have proof for why he needed to have his handcuffs removed, so he could sign, of course. It's the same concept as how hearing people can't have their mouths taped. Next, when I talked with him, he said he couldn't understand me and asked me to repeat myself several times. I asked him if he had known sign language growing up. He said yes, he grew up signing and went to a school for the deaf. I asked him why he didn't understand. He said it had been 25 years since he had last interacted with another Deaf person. That is language deprivation. There is a lot of talk about language deprivation among children, but that exists for adults as well. That is the policy and research we need to prove that Deaf people must be able to interact with each other and sign throughout their lives. Deaf people cannot be in isolation, no. That is an example. That's why we are suing so many prisons. We have to make them stop. They must provide interpreters for Deaf people, and stop separating Deaf people. Many prisons express concern that if Deaf prisoners are placed together, they'll come up with secret signs and formulate plans to escape. Really? That's wrong. So we must have research on that. Fine, we can hire Deaf people as guards. That's an example. Plus Opeoluwa mentioned the future. As another example, future cars might be self-driven. We wouldn't have to do anything and could pull up to each other and sign with each other. But how would you tell the car where to go? They're doing research and building voice-activated cars. Time out! Zainab and I have been going to meetings with different companies and telling them that we need to have a way for Deaf people to sign or type interactively with the car in multiple ways. There needs to be a way for that technology to understand us and where we want to go. That's an example of research that you could do and provide to us, so we can use it to talk to them about it. If they won't listen, we'll sue.

\section{ZA: Exactly.}

THH: You mentioned the need for research, like some said artificial intelligence, handcuffs on Deaf people, the importance of Deaf interaction, and language deprivation in adulthood. What other data and research do you feel you specifically need for your work? I'm curious. Can you share?

HR: Your field! Education!

THH: That's true. That's a long list! We need more research in the area of education. Laurene Simms can confirm that! Yes. A lot of research is required for education. That was good how you asked me my own question. Okay. A lot of questions that need answers have to do with what kind of learning environment is best for a Deaf child. That's where it's weak; research findings for that are inconclusive or unclear. 
We must find what the best learning environment is for Deaf children as well as what kind of adults and professional training are the best fit. Some schools might have undergone some training, which has pros and cons, but they haven't reached that level of understanding of the impact yet. We really need more research so that we can compare data on tests and training, the preliminary set-up, post-training results. If there are a lot of positive outcomes, then, perfect! We can push for additional training. We need more of that kind of data, for example.

OS: I want to add to that. For two years straight, Missouri filed a bill for LEAD-K. Are you familiar with that?

Panelists: Yes.

OS: You know. Okay. Some states have filed bills. For two years straight, we fought for it but it failed...

HR: Oh, yes.

OS: ...because we don't have the right data and verification. We had some and borrowed ideas, but it was more of a political issue, a hot issue, between the NAD, A.G. Bell, and the LEAD-K group in California. That issue appeared two times in a row. This year, my councilor let me know that I should hold onto our bill and not file again. The reason was because they felt we need more time to educate Missouri. So maybe next year - we're hosting the Deaf children education summit, so we can come together and discuss what we want and our goal in working together. But I think maybe we need more research to really verify that. There is existing research that shows kids who grow up with bilingualism are smart. I grew up speaking eight languages before becoming Deaf then I added ASL and International Sign. Now I know 11 languages and I'm proud of that.

THH: Wow.

OS: Many deaf children are the same and will benefit from it, and we need to show them. We need proof for that.

THH: True. Being bilingual doesn't necessarily mean one knows only two languages. It means one knows two or more languages. When children acquire languages, they can learn other languages and use all of them seamlessly. For children, the more languages, the better.

HR: You mentioned education and language, but we need more research in many other areas. For example, mental health.

THH: Absolutely, yes. 
HR: Often when Deaf people go to therapy, will they be placed with an interpreter along with the therapist? Here in America, many consider that problematic. What happens when a Deaf person goes to a therapist is the therapist asks "Do you hear voices?" - a common hearing question. The therapist means to ask if the person experiences or sees something that is not there, like people talking in that person's imagination. But if an interpreter signs that word for word, "Do you hear voices?", the Deaf person might say, "Yeah, I wear hearing aids." That misunderstanding could lead to a misdiagnosis and incorrect prescription of medicine. That is one simple example. Hearing therapists don't have this cultural understanding about Deaf people. There is already some research, but there needs to be documented data to prove that we need Deaf therapists, or a therapist who is a fluent signer and understands Deaf culture, rather than using a third party. There are many experts in the audience I see who can do that. So, mental health, and as Zainab said, transportation. Police, which Opeoluwa has researched, prison conditions, and different technologies are other examples that need to be studied. And even Deaf space. Here's a recent example. We fought the government, since the government banned homes dedicated to Deaf senior citizens, saying they weren't allowed. But such buildings incorporate Deaf space in lighting, windows, and accessibility such as videophones inside each home. Even the front desk is accessible with visual alerts. You know how we Deaf people sometimes forget to turn the faucet off and it runs for a long time? There is a technology that uses a light to alert us. That's handy. There are a lot of other innovations designed with Deaf people in mind. We need more homes like that, but the government thinks that deaf people in one place like that is a "deaf ghetto". That's a mistaken perception. Deaf people want to be together because of that full communication access. That's healthy. Many Deaf senior citizens are alone in nursing homes spread out across the country. That's not a great way to grow old. We need interaction. We need to change government policy. We need data.

THH: Thank you. I will move on to the next question then hopefully have time for the audience to ask questions.

ZA: I haven't responded.

THH: Do you want to add to that?

ZA: I want to add something, if you don't mind?

THH: Go ahead. Sure, go ahead.

ZA: Thank you. We have a lot to say. I'll share my response then let you share yours. A lot of my work is related to technology, so we need data and research related to that. Like Howard mentioned, self-driving cars, or Internet of things, and the concept of smart home devices, like smart refrigerators or washing machines. All of them are designed with hearing people in mind and use interactive voice activation technology. Where is the technology for Deaf people? They need to start designing with Deaf people in mind. Often they do not and proceed with their ideas, leaving Deaf people behind. We tend to have to chase them and try to keep up. 
No, we need to be included from day one, from scratch, from the start, and build in the accessible technology for Deaf people. So we really need the data to be ahead of the curve, not later but from day one. That's what we need.

THH: True. Joseph?

JM: Yeah, I want to go back to the topic of education. On an international level, if inclusive education becomes the standard around the world, the government will feel obliged to follow the expectations. What does inclusive education mean? It depends on who you ask. Whoever you ask today, tomorrow you might get a different answer. I've seen many differences. Some think inclusive education means Deaf children must be immersed, often sinking, in a hearing environment. That's what they call an inclusive education. Other views on inclusive education - I recently visited one country, a deaf school, not an institution but a deaf school. The government said, "Oh, inclusive education? Yikes." They removed some of the deaf students aside and replaced them with hearing students and said, "Okay, now it's an inclusive school." Those Deaf students had nowhere else to go, not even other schools. That was considered inclusive education. WFD just released a position on inclusive education explaining the holistic concept, meaning children have the right to gather with each other and have the right to communicate with peers, support staff, and everyone around them through sign language. I went to the United Nations and was asked what an example of good inclusive education was. I pointed to America, but they quickly said America was a rich country so it wouldn't be a part of their consideration because that concept couldn't be applied to the rest of the world. So I need you to do that research and tell me what works with the concept of inclusive education in different countries. What works for your countries? What works? Give us good examples or give us examples of why inclusive education doesn't work. With that information, I can have arguments showing what is effective or not. At WFD, we believe that inclusive education can range from deaf schools to twin schools to other forms of education. Some Deaf children grow up and then at 14 or 15 they want public education with interpreters and that's fine. If they feel they have access to language and their environment, that's fine. There's that range. We need examples from different countries, different economic statuses, and different areas in the world. We need that research. If some of you are Ph.D. students considering what to do, see me, please.

THH: It made me realize that it seems you need stories, too. Does that apply to your work?

ZA: Yes.

THH: Stories of your experiences with the world, school, telecommunication, technology, employment, and so on. Your stories are important. Document those experiences, and we can identify similarities and use that to help us in our work. That' $\mathrm{d}$ be terrific. Now, I want to ask a question that tends to come up. I'm curious what your perspectives are.

ZA: That's a hot question.

THH: Are Deaf people a disability or linguistic minority? Take a moment to ponder that. 


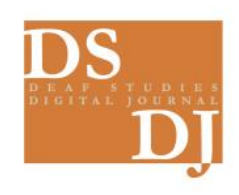

ZA: I think we all agree.

JM: Do we?

THH: You may respond with "both" or "neither" if you prefer.

OS: In my opinion...both. The reason for that is you're asking me to divide myself into two parts. Can I live with it? I can't. It's who I am. I'm Deaf. I know I have a barrier. It's a disability, and that's clear. My language is ASL and I want people to recognize sign language and the fact Deaf people, especially children, have the right to access sign language. Division — why did you ask?

THH: The reason why — did you want to say something, Howard? The reason is because I noticed research often says one or the other, rarely both. That's why I'm curious what your perspectives are. You can say both, sure.

HR: I've been working in the field of civil rights for 26 years. I'm old, okay? Actually, probably the oldest in this group. This is tough. I know people ask me how I feel about the disability label. Here in America, we have no language rights at all. It's starting to emerge here and there, but if you speak another language and want rights, there are only two areas where that access is required. In court, whether you are guilty or not, they must provide language access for criminal court only. For civil court, like if someone wants to buy a house, get a divorce, or adopt, there is no requirement to provide an interpreter. That's for criminal court only. The other requirement is for hospitals. Hospitals must provide language access for patients to communicate with their doctors. So only these two areas. For education, transportation and other areas like university education, there are no language rights. Zero. America has been trying to get ASL recognized. English is "unofficial". It's used, yes, but is it officially recognized as an official language? No. If you want to say we're a linguistic minority, we'll be waiting for a long time in America. I doubt it will happen anytime soon. Given the political climate - oh, boy. To those from another country, I apologize. Go vote on Tuesday. Thank you for the reminder. Vote on Tuesday, please. So, what gives us rights? Our disability. I understand we might not feel that we're disabled. I tend to say that we do not have a cultural disability. We have a legal disability. Culturally, we are a linguistic minority, but legally, we have a disability in order to qualify for services. That's my pragmatic approach, trying to figure out how to use the system for us. In a perfect world, we would be a linguistic minority, not a disability minority. But for now, we have to use the system to our benefit. That's my point of view.

THH: That often depends on each country's ideology. Some countries welcome the recognition of different languages from signed to spoken. It's important you know your country's ideology. Howard just explained the ideology of the United States. We have a language that is not federally recognized but commonly used. That's for the United States, but in other countries that varies. I'm curious to see what your experiences have been in navigating the system to recognize your language in your area. Some already have. Was it 46 countries, Joseph? 
JM: 45.

THH: 45 countries have nationally recognized languages. That's impressive. The United States is eagerly anticipating when we can become part of that club, I'm sure. We'll see. Joseph, did you want to add anything?

JM: Yes. Again, Ben Bahan shared some information and showed WFD's statement on Deaf people. Do Deaf people belong to a linguistic minority or disability minority? Some people in this room helped write that paper. You can find it on the website. In summary, both ideas of linguistic or disability minorities are concepts. Deaf people's lives do not fit either group 100\%. Concepts from both groups are used to achieve our equality. Equality is achieved through language rights, but we use disability access. A total of 45 countries have sign language laws. It's interesting to see the differences. A lot of those laws passed the law to recognize sign language, but does that language recognition apply to everyday life? Perhaps, perhaps not. If you want access to interpreting or access to information, it tends to be through the disability category. If you go to a surf or turf, you can say you want both. Use both concepts.

THH: I think that's a little too much food for me! I would rather have soup and salad. I wouldn't mind that. Opeoluwa, do you want to add something?

OS: Some states in the United States already recognize ASL, such as Missouri -

HR: Right.

OS: - but really, that recognition exists only on paper. Actually working on it or practicing it? Not quite. We are fighting for policy change on paper, but for making people change their culture and attitude towards ASL, that's some of the areas we have to think about.

THH: Thank you for adding that.

ZA: I was right, we all agree. But I'm a lawyer, I look carefully at the wording. The question is, "Are we...?" Yes, that is the reality. We are recognized as a disability minority. We use disability laws to gain accessibility. But is the goal that we should be recognized as a linguistic minority? That's the question. The goal we want is to be recognized as a linguistic minority that cherishes ASL. That's how we want to gain accessibility, rather than through our disability. But like Howard said, that's a long way off. But should it be that way? Yes. Reality is different. Will that change, and when? That's up in the air.

THH: Thank you. 


\section{PUBLICATION FUNDING}

This conference proceeding was made possible with the financial support of the National Endowment for the Humanities, Digital Humanities Advancement Grants [\#HAA-258756-8, 2018]; and Gallaudet University: the Office of the Chief Bilingual Officer, Yeker Anderson Club, and Department of American Sign Language and Deaf Studies.

\section{PUBLICATION TEAM}

Patrick Boudreault, Editor

Tawny Holmes Hlibok, Conference Co-Chair, \& Assistant Editor

Matthew Malzkuhn, Conference Co-Chair, Assistant Editor \& Video Editor

Ivy Davis, Production Editor

Brianna Keogh, Production Editor

Andrew Biskupiak, Production Assistant

Dirksen Bauman, Advisor

T.S. Writing Services, LLC

\section{SUGGESTED CITATION}

Hlibok Holmes, T. (2020). The Transformative Impact of Deaf Studies on Law and Policy. In P. Boudreault (Ed.), Deaf Studies Digital Journal, Vol. 5: Selected Papers from Deaf Studies Conference Transformation 2020, https://doi.org/10.3998/15499139.0005.009 